\title{
Postcolonial Approach to Amitav Ghosh's The Shadow Lines
}

\author{
Hamid Reza Kasikhan
}

\author{
Assistant Prof. of English Literature, Department of English Language, Yadegar-e-Imam Khomeini (RAH), \\ Shahr-e-Rey Branch, Islamic Azad University, Tehran, Iran \\ h.r.kasikhan@iausr.ac.ir \\ hrk1962@gmail.com \\ Naghmeh Kasikhan \\ BA in English Literature, Alzahra University, Tehran, Iran \\ kasikhannaghmeh@gmail.com
}

Doi:10.5901/mjss.2015.v6n4s3p247

\begin{abstract}
The present article turns round exploring the elements of postcolonialism in one of Amitav Ghosh's novels: The Shadow Lines. He has interwoven and scrutinized the impacts of colonialism on the culture and society of two main neighboring cities, namely Calcutta and Dhaka. Presenting a thorough political and cultural change, the novel throws light on initial awareness of the social, psychological, and cultural inferiority enforced by colonizers, and displays struggle of subaltern people for ethnic, cultural, and political autonomy. Throughout the novel the writer explicitly and implicitly emits sparks or traces of postcolonial principles to show his interest in depicting the aftermath of colonization especially in an era after the emancipation. The article, therefore, aims to explore the overall structure of the novel through postcolonial approach and provides examples from the novel regarding the application of some postcolonial elements such as obscurity, memory, imagination, identity, essentialism, otherness, ambivalence, nationalism, space/place, worlding, diaspora, hybridity, unbelonging, independence...etc.
\end{abstract}

Keywords:Postcolonialism, Amitav Ghosh, The Shadow Lines, Hybridity, Calcutta, Dhaka

\section{Introduction}

This book won Sahitya Akademi Award and brought fame to its young Indian-Bengali writer: Amitav Ghosh. The novel incorporates perspectives of time and events and holds dualistic approach toward other entities, such as twofold application of lines that once bring people together and once detach them from each other; an existent and sometimes non-existent entity that is both visible and invisible. The novel functions as mental web criss-crossing physical and mental boundaries, probing memories of people through linking past and present, and inviting reader to invent personal memories or imaginations that project various shades on same experiences.

The novel recollects historical events as Swadeshi Movement, Second World War, Partition of India, and riots of 1960s in Dhaka and Calcutta. The main parts of the novel centers round the consequences of drawing lines around ourselves and our nations, seeking identity in the absurd, hectic world today and being in quest of political freedom to revive nationalistic spirits. The novel spans three generations spreading over Dhaka, Calcutta and London. Taking advantage of the element of hybridity, the writer adeptly collects characters from various nationalities, religions and culture to compare and contrast their resemblances and discrepancies in identity, ideology, language, race, ethnicity, alterity, space/place, and their viewpoints toward the world and its boundaries. The article aims to study different aspects of the novel, including characters, events and ideas through the framework of postcolonial approach.

\section{On Amitav Ghosh}

Indian writer who was born in 1956 in Calcutta and studied in Delhi and Oxford Universities, obtained his PhD in Anthropology and composed many other novels while dwelling in New York, Calcutta, and Goa. Some of his works include The Circle of Reason (1986), The Shadow Lines (1990), In An Antique Land (1992), Calcutta Chromosome (1995), Dancing in Cambodia (1998), Countdown (1999), The Glass Palace (2000), The Hungry Tide (2004), Sea of Poppies (2008), River of Smoke (2011)...etc. Moreover, he completed a series of articles entitled The Imam and the 
Indian (2002) that revolve around fundamental issues on philosophy, history, culture and literature.

\section{Plot Summary}

The events of the novel turn round the family of the young middle-class boy protagonist (i.e. the narrator), the Datta Chaudharis, and Prices family in London. Tridib, (the second uncle of the narrator) is much praised by the narrator because he (Tridib) is endowed with enormous general knowledge and has peculiar and eccentric attitude to events and places. Tridib teaches him (the narrator) to use his imagination with precision and in this way helps him being released from the boundaries surrounding him. In contrast, when Tridib gets killed at the end of the novel, his family does not regard this tragic incident seriously and try to forget and ignore it, but the narrator begins searching to find out the reason of his murder, as he feels he owes his new outlook of life to him. One of the major characters of the novel is Tha'mma (narrator's grandmother, very strict and disciplined) who does not approve Tridib's behavior and believes he is just dissipating his life by roaming and wandering in the corners of streets, and so he (Tridib) fails to establish a respectable career despite having good family connection. Tridib's peculiar character and viewpoint seem fascinating and appealing to the narrator and he (narrator) enjoys listening to him, as he believes Tridib's knowledge is exceptional and extraordinary. Tridib falls in love with May Price (daughter of Prices family) and endangers his life to save her from the potential threats in the communal uprising of 1963-64 in Dhaka. Likewise, the narrator is emotionally bound to lla (his cousin and a very good looking lady), but never expresses his feelings verbally to her, fearing that he may lose this relationship. When Ila, becomes unexpectedly informed of his fondness to her, feels sorry for him. It is worthy to note that Ila is excessively hated by Tha'mma who calls her with offensive and insulting attributes. She (Tha'mma) never likes her grandson (narrator) either, as he supports lla. The tragic life of Tha'mma in the past prompts her (Tha'mma) to reunite the family and therefore, goes to Dhaka to persuade her uncle, Jethamoshai, to move back to Calcutta.

The novel enters round three generations of the narrator's family who live in Dhaka, Calcutta and London. It embodies a wide-range of characters picked up from diverse religions and cultures put beside each other in a unified comprehensible setting. The commencement of the novel is 1939 when World War II broke out, and is terminated in 1964 that follows the beginning of violence, riots and uprising in India and Pakistan. The 8-year-old Tridib, the narrator's father's cousin was taken to England in 1939 and got killed by a street mob in Dhaka in 1964. Therefore, the shade of death, violence and terror is quite palpable throughout the novel, and that the hostility and lines detaching people from each other seem common and ordinary. The events of the novel do not move forward in a linear direction, but proceeds irregularly in a cyclic movement weaving the experiences of the narrator as well as those he sees by the aid of memory and imagination.

\section{On the Novel}

The novel is centered on depicting lines that make people far from each other, and are sometimes visible and invisible depending on alternating perspectives. The narrative sounds like an intricate web intertwining characters' memories and imaginations. It seems that the writer is not intended to narrate a story and instead, invites readers to create one through their own imagination.

Definitely, Ghosh is not the first Indian writer probing colonial issues and writing about unwanted detachment of people from each other. The educated writers of this country have always written on India and Bangladesh simultaneously, as if the perplexing fate of these two nations has been imposed on them by the force of time and history, and has connected their cultural and political destiny and identity to each other. Being rich of such themes, Ghosh explores human relationship in the midst of historical, cultural and political conditions - as colonizer and colonized relationship - in his novel.

As a postcolonial literary work, the novel turns round self-conscious contemplation of themes as nationality, internationality, cultural and historical self-determination. The novel examines the transitory movement from elevated desire of struggle for nationalist freedom to insight, awareness and enlightenment.

\section{Elements of Postcolonialism}

The Shadow Lines addresses the problems and consequences of a decolonized nation and brings into surface the political and cultural difficulties that any de-colonized nation normally faces. Problems as identity, crisis, suppression, resistance, gender and exploitation are mainly highlighted and dealt with in this novel. The text discloses cultural differences, the ways in which race, religion, class, gender, sexual orientation, cultural beliefs, and customs combine to 
form individual identity in shaping our perceptions of ourselves, others, and the world in which we live. It also includes the relationship between personal and cultural identity and such issues as double consciousness and hybridity.

\subsection{Obscurity}

The character of the narrator whose name remains unnamed till the end of the story seems interesting and thoughtprovoking. His main role and figure and his pivotal portrayal throughout the narrative is reminiscent of a colonizer who intentionally attempts to remain unseen. He comments on everyone and everything, his ideas and his consecutive descriptions of the emerging memories are considered significant, but his ambiguous character stays behind one of those shadows that Ghosh talks about. The deliberate intention of the writer in keeping the narrator's character as vague and obscure as possible, is justified when one notices that almost anything is described in detailed precision: the exact mailing address of the Prices, the brand names of most objects, as Rennie's digestives tablets, Lyon's assorted toffees, that the watch is Omega or cars are Studebakers...etc. Despite all these precise descriptions, there is one blank space: we never get to know the narrator's name, nor can we visualize how he looks like.

This point can be interpreted and looked at differently too, implicitly claiming that the narrator symbolizing colonized people is so inferior, unimportant and subordinate that is not seen by colonizers and therefore, no definite portrayal or image of him is presented.

\subsection{Memory, Imagination}

Like Tridib, his mentor who bestowed him (the narrator) the gift of imagination, the narrator has a deep desire to travel around the world. Both (narrator and Tridib) enjoyed a distinct sense of mental journey to locations they had not visited at all. This special relationship is so close and intimate that the narrator can remember almost everything about the time and place they had been together even after Trideb's murder in a communal riot. It is the space of memory and imagination that link them together emotionally. The deep and powerful effect of Tridib on the narrator that is unilateral and reminiscent of colonizer-colonized relationship scares the grandmother and makes her order her grandson (the narrator) to avoid Tridib. Being tired of all social pressures, the narrator regards Tridib as a hero who can help him get rid of all kinds of restrictions. For him, Tridib represents openness toward space and place, capable to use his memory from the past to connect with the present. The narrator symbolizes a colonized nation who is in quest of anything or anyone who renders him a sense of triumph, openness and freedom.

Memory functions a pivotal role in this novel as it determines one's perception of time and our identity. Due to being unable to change history, one usually takes advantage of memory compatible to his or her viewpoint. Yet, the memories that one chooses to forget are more important than the ones one chooses to remember, and this is the key point that Ghosh attempts to impart to his readers. Memory as an abstract entity exceeds the bounds, transcends the time scale, and moves beyond any kind of restrictions. Therefore, constant shift of time, going back and forth, and incessant transfer from present to past and conversely, is another appealing factor attracting the readers' attention.

Since young age, Tridib persuades the narrator to use his mental faculty and imagine places he has never been to and conjure up the incidents he has never experienced in real life. Through the narrative, historical facts and personal experiences are simultaneously dwelt in his memory, "Tridib had given [him] worlds to travel in" (Ghosh 21). This natural conceptualization and power of fancy ultimately becomes the narrator's guide in his life and helps him mentally see almost everywhere outside Calcutta. Imagination even enables him to invent and see places in his mind that do not exist at all. Such imaginative faculty becomes so deep-rooted in the narrator's character that forms his new identity and makes him distinct from the others.

Having used the power of imagination, the narrator is able to see various places or spaces. As a young school boy, he imagined London so clearly that he could easily recognize places just by their names when he visited London some years later. Power of imagination enables him to travel in real and imaginary places in 'fading photographs'(Ghosh 59), reading maps in 'his tattered old Baltholomew's Atlus' (Ghosh 230), the old newspapers, 'faint recollections' (Ghosh 19) of childhood memories and games. In this narrative, Tridib and the narrator are the only people who attempt to run and conduct their own lonely lives and create their own stories. The fact that they want to be different from the others corresponds to the element of alterity or otherness.

In The Shadow Lines there is persistent emphasis on the freedom of individuals to create their own stories distinct from the others to avoid being mixed with someone else's construction of reality. Perhaps that is why Tridib persuades the narrator to learn imagining precisely and creating his own world. Being able to invent stories makes one independent from other people's invention. Such persuasion and encouragement can metaphorically denote independence, autonomy 
and freedom from everything that are presented or imposed on one by others. In a larger scale, it seems that Ghosh attempts to impart that there are no subaltern people or any colonized state as long as they are independent from the other's invention.

\title{
5.3 Identity, Essentialism
}

Since the commencement of the novel, the problem of identity is deeply felt. This problem is not merely confined to characters, but places and locations as well. In the opinion of the narrator, the identity of a location is normally formed and established by the means of stories, photographs, maps and memoirs that can be invented by one's imagination. This procedure (imagination) seems like a psychological process by which one can successfully indulge his or her suppressed fancies and gratify the whims they have been looking for but failed to attain in real life. Identity potentially involves 'essentialism' and 'othering', two other significant terms in postcolonialism.

Essentialism, in definition, is the essence of whatness of something. Regarding race, culture, or ethnicity, essentialism refers to the practice of different groups in making decision what is and isn't a particular identity. Practically speaking, essentialism tends to ignore discrepancies within groups to maintain the status quo or with the aim of obtaining power. In essentialism, all sides involved, colonizer or colonized, resist their standpoints. In this novel, despite few characters, the majority of characters involved tend to retain and preserve their own already held status and seldom dare to welcome changes or even choose among multiple options they may come across. So, it can be named as an element of defiance, resistence and confrontation to achieve, keep or choose what is believed to be theirs. Trideb says "Everyone lives in a story... because stories are all there to live in, it was just a question of which one you choose..." (Ghosh 182).

\subsection{Otherness (alterity), Ambivalence, Nationalism}

Othering, as another postcolonial element, is the social or psychological way in which one group excludes or marginalizes another by declaring them 'other' to emphasize that what makes them dissimilar from or opposite of another lies in this otherness, and it depends on the way they represent others, especially through stereotypical images, showing behavior which is repeated without variation, and is irrespective of circumstances. Tridib is a perfect example of such otherness: he has used his education for personal liberation and has conducted his life based on his own choices, and is therefore, happy the way he is. Unlike others, he views the world as a mosaic of interconnected locations devoid of border. To him, all places of the world are parts of each other without slightest degree of superiority or inferiority. His power of visualization that was later taught to the narrator and opened a new horizon of the world in him, makes him distinct from the others.

The concept of otherness, in this novel, is twofold with doubled meanings, and hence moves nearer to the concept of ambivalence regarded as another element in postcolonial texts. Otherness does not necessarily mean being different or dissimilar, but is sometimes meant 'another identical image'. The narrative undermines the imagined differences between Dhaka - as a newly created nation - and Calcutta through the application of mirror. These two cities are so culturally and socially identical that looking at one is sufficient to claim that the other is being looked at too. Such lookingglass border emphasizing the similarities of these two towns is deeply rooted in an ancient history of the past when people could travel without showing passport or identity card:

\begin{abstract}
the simple fact that there had never been a moment in the four-thousand-year-old history of that map, where the places we know as Dhaka and Calcutta were more closely bound to each other than after they had drawn their lines - so closely that I, in Calcutta, had only to look into the mirror to be in Dhaka; a moment when each city was the invented image of the other, locked into an irreversible symmetry by the line that was to set us free-our looking-glass border. (Ghosh 233).
\end{abstract}

In addition to Tridib and narrator, lla is also one of the unique characters who is naturally different from the others. Despite her numerous travels around the world, she is unable to invent a place in her mind as she believes all places are the same, and this baffles the narrator with the 'mystery of differences' (Ghosh 31). To her, just the physical existence of a place is a matter of significance. She is mentally incapable to recall the past and when asked the reason, she shrugs and replies: "It was a long time ago, the real question is, how you remember" (Ghosh 19). This answer dejects the narrator as he sees that his cousin (Ila) has no concept of place and fails to invent one in her mind and that she completely relies on the invention of others:

I could not persuade her that a place does not merely exist, that it has to be invented in one's imagination; that her 
practical, bustling London was no less invented than mine, neither more nor less true, only very far apart. It was not her fault that she could not understand, for as Tridib often said of her, the inventions she lived in moved with her, so that although she had lived in many places, she had never travelled at all. (Ghosh 21)

Travelling and exploration of boundaries is the writer's main purpose. Having underlined the concepts of alterity and otherness, the writer focuses on nationalism, emphasizing that the shadow lines we draw among ourselves, people, and nations is not only an absurd illusion, but also can be a source of bloody violence. These shadows, appearing in the form of national boundaries, manipulate private and political spheres, and meanwhile display people's struggle to overcome artificial borders.

\subsection{Space/Place}

Space or place in their common meanings 'location' plays fundamental role in the fictional realms of Ghosh and his protagonists who are obsessed by space, either imagined or remembered. He can make bridge among people, places, ethnicities and communities to demonstrate the power of "overlapping territories, intertwined histories" (Said 3) in our daily-increasing interconnected world. Place in his narratives, local or global, seen or unseen, is conceived as an important aspect of individual, national, familial and communal transformation.

In a postcolonial text, space, place and identity play significant roles, as it is the place that normally renders identity and reinforces vehement nationalistic passion. Space represents a geographic or abstract locale, an empty room or area not being designated for any specific purpose. Place, on the other hand, refers to the scene or occurrences when a space is made or owned. It potentially includes landscapes, language, environment, culture...etc. Identity is the way in which an individual or a group defines itself. The importance of it can be traced in self-conception, social mores and national understanding.

The places described in this narrative are many. Ghosh says that a place must be 'a part of history' (Ghosh 104). Trideb had lived in 'their old family house in Ballygunge Place with his aging grandmother' in Calcutta (ibid. 6), England (ibid. 11), Banaras (ibid. 8), America (ibid.), London (ibid. 15), Delhi (ibid. 20). These places, according to Marc Augé, French anthropologist, are places that have a history; they are relational and are associated with identity. Place, he asserts, "can be defined as relational, historical and concerned with identity." (Augé 77). So, these places have identity because they have a present, a past and a future. Place represents a geographic locale, it involves landscape, language, environment, culture.

\subsection{Worlding, Diaspora}

Meanwhile, the concept of worlding, as another postcolonial element, is brought into surface: the process by which a person, family, culture, or people is brought into the dominant Eurocentric/Western global society. Worlding can be done either at one's own discretion as in voluntarily migration to a new location, or by force as in colonized states. The fact that characters change their living places, either willingly or compulsorily, and the fact that numerous settings are mentioned throughout the narrative, is reminiscent of diaspora, another postcolonial principle that is concerned with the migration of people from their native homelands. The literature of the novel is directly or indirectly related to the questions of migration or altering identity, language, and culture.

The concept of travel or worlding is ubiquitous throughout the novel. Regardless of whether or not this journey or traverse is willingly or compulsory, this concept is pervasive in every part of the narrative. As a result, one faces many references linked to history and geographical spaces. The author names India, Bangladesh, England as the main geographical locations; India's war with China in 1962; Nazi-Soviet pact (Ghosh 67), riots in Calcutta (ibid. 221), riots in Dhaka (ibid. 252), Hazratbal (ibid. 224), newspaper references to riots (ibid. 254), cricket test match of 1964 series (ibid. 199) and many others. Moreover, the division of the book into two parts, namely 'going away' and 'coming home', associates the idea of traverse. 'Going away' begins in 1939 when Mayadebi flies to England with her husband and her son, Trideb; and 'coming home' concerns with the coming home of the narrator to his motherland, India.

In postcolonial texts, the term diaspora refers to the voluntary or imposed migration from the native homeland with the aim of deciding whether or not to alter identity, language, and culture. As far as the concept of diaspora is concerned, both (narrator \& Ila) are diasporic, having experienced displacement from their native homelands across the globe, but in different ways: one physically, the other imaginatively. The narrator holds the belief that "a place does not merely exist, that it has to be invented in one's imagination; that [lla's] practical, bustling London was no less invented than [his own], neither more nor less true, only very far apart." (Ghosh 21). 
Colonization transforms subaltern people into victims who may forget their real locations and identities: where have they come from? Or where do they belong to? Consequently, the difference between coming and going is undermined and vitiated. Perhaps that is why Tha'mma, the narrator's grandmother, erroneously asserts that she is 'coming' to Dhaka. It not only suggests that any departure must be followed by a return, but also implies that subaltern people are psychically confused and can hardly obliterate the era of barbed wires and checkpoints on their old territories from their minds.

\subsection{Hybridity, Unbelonging}

The concept of hybridity functions as a key element of postcolonial texts that is well cultivated in this novel. Literally speaking, hybridity refers to the state of being mixed. It denotes the possession or occurrence of fusion, merging and homogenization. Hybridity in literature focuses on the effects of mixture on identity and culture. Hybridity can be traced in most fundamental entities highlighted in the novel, such as language, place, time, identity...etc. For instance, the narration vacillates between Bengali (that of narrator) and English. The narrator holds a hybrid identity, as he is born in India but received English education. So the whole story moves back and forth between India and England. It is true that the English language had never been the formal language of Indians before the colonization. So the fact that Ghosh writes in English may indicate a kind of alienation from what was once standard of nationalism.

Tha'mma (the narrator's grandmother) dislikes and denounces such hybridity and believes that strong feelings of Indian nationalism and patriotism should be reinforced. Her ideal is a homogeneous society with clear borders. So it seems unacceptable to her to allow lla to live in London, as she believes "she does not belong there" and "she has no right to live there" (Ghosh 77). The grandmother is a sort of character who defies and withstands hybrid entities or any kind of heterogeneity. Having ardent nationalistic passion, she holds the view that a nation is formed by people who shed their blood for its independence. She claims that "they are a nation because they've drawn their borders with blood...war is their religion" and that this is "what it takes to make a country" (Ghosh 78) supporting that the same has to be done for India, in order to build a homogeneous national identity.

Although geographical lines and military borders may lead to fixed identities and distinct nations, culture is still diverse and differs from community to community. The history of India and England has been bound and dependent on each other. The title The Shadow Lines, therefore, implicitly alludes to the point that there are no clear boundaries amongst people who have lived with hybrid and diasporic identities for a long time.

Even Tha'mma, the most fervent nationalist figure, seems oscillating between two identities: whether she belongs to Dhaka or is a citizen of Calcutta. In her bewilderment, rather than saying that she would go home to Dhaka, she says that she would come home to Dhaka. Although she was instantly teased by her grandson for such slip of the tongue between coming and going, it denotes a deeper reality: she is caught between memory and nationality, between belonging and citizenship. Naturally, the grandmother's unbelonging can be ascribed to the product of the circumstances of her life and history. She is bewildered why her birth place should be at odds with her nationality and that why she should be like a foreigner in her home town, Dhaka, after years of being away from it. The grandmother was in quest of "a word for a journey that was not a coming or a going at all; a journey that was a search for precisely that fixed point which permits the proper use of verbs of movement" (Ghosh 153); and this fixed point seems inaccessible to her because of her dislocation.

Likewise, there is no natural home for Ila. She feels uncomfortable in Calcutta and finds its social environment tough and unbearable. She believes that she must find or create her own place in the world. So she flees Calcutta to seek a home in London. She marries an Englishman, buys a house, finds a job, tries to settle down, but all in vain. She escapes Calcutta because she was in quest of freedom, a freedom that brought rootlessness. Both Ila and Tha'mma share a common point: they are unimaginative, unfree, rootless, and blind to the realities of the subcontinent's history.

The kind of hybridity employed in this story is not merely confined to characters' identity, but includes various aspects of their approaches to life, as in love and politics. For instance, there is romantic love, best illustrated in Tridib's vehement passion to May Price that despite their distance remains deep and ardent in him. Similarly, the narrator is emotionally bound to her cousin (lla) that grows from adolescent infatuation to adult passion. The positive outlook of male characters to the concept of love is contrasted with the negative attitude of females as lla and Tha'mma that finally lead to an unsuccessful relation. Ila's emotional feeling to Nick Price is much inferior to love, because in spite of his betrayal of her in their childhood and his repeated infidelities thereafter, lla still shows a kind of unjustified, groundless and masochistic passion to him. Similarly, it is the narrator's grandmother who evinces negative aspect of love most disastrously, and fails to accept lla as her grandson's suitable love.

In contrast, they are female characters who show courage and strong determination in the field of politics. Both lla 
and grandmother are interested in political movements and feel they should actively participate in events to remain perpetual in the course of history. Conversely, passive male characters, mainly Tridib and the narrator, are just observers of political events rather than being participant. The collection of characters chosen from two opposite extremes renders novel a quality of hybridity that corresponds to a heterogeneous society as India and Bangladesh.

Each element of the novel, as the title suggests, is a sample of both shadow and lines. Illusory national borders, standing for lines among nations and people, the ubiquity of time and space that fluctuate between reality and non-reality, all are examples of a hybrid microcosmic world that is not solely restricted to one geographical area. Despite the careful chronology and topography of the setting, the events of the story can happen in all places and at all times. There is no separate or isolable spot of time and place. The precise mention of dates and locations only draws attention to the sameness of the underlying essential experience.

The fragmented reflection of the past uttered by various characters represents Ghosh's diasporic identity mirrored in this novel. Such broken and scattered images of the past permit the writer to magnify cultural differences and lets him widen space for a multicultural definition of the self to emerge and hybridity to be embraced. Paradoxically, diasporic displacement is not merely and completely a loss, in fact it may appear as a source of creativity, because new polyglot and cosmopolitan cultures can be brought into surface as the main products of such hybridity.

'Use of imagination with precision' (Ghosh 30 ), the technique taught by Tridib to the narrator, helps the writer create a hybrid atmosphere of time in which past, present and future merge and combine. It helps the narrator see the past as contemporary to the present, see historical memory as dynamic and lively to the understanding of the current situation, and be able to see different times and places as inextricably intertwined with one's own. Constant interchange of reality and imagination in the transcultural consciousness of the narrator makes him believe that reality does not lie in perceptible and apparent entities, but in what is perceived and reinforced by the shadows of memory. His belief in imagination is so firm that claims no one can see a place unless he or she imagines it in his or her mind. To him, only imagination is capable to present a lucid and enduring picture of reality.

The development of the story illustrates a kind of hybridity shown in interweaving of the strands of space, memory, history and nation. Bose asserts: "In Ghosh's fiction, the diasporic entity continuously negotiates between two lands, separated by time, space, history and geography, and attempts to redefine the present through a nuanced understanding of the past." (Bose 239). The narrator constantly moves back and forth in time and space signifying that the past lives in the present and that the present is shaped by the past, or in the novelist's words, "the past is concurrent with the present" (Ghosh 31).

The chronic structure of the novel resembles a rug or a carpet (one of main oriental handicrafts) in which wharf and woof are laid on each other. Ghosh exceeds the boundaries of time and lays past over present, and sometimes does it conversely. Moreover, the bounding lines of fact and fiction, reality and unreality are dissolved and this permits Ghosh to move on three distinct timelines: 1939 when Trideb goes to England along with his family and his mother, 1964 when Trideb goes to Dhaka with Tha'mma, and 1981 when the narrator goes to London for his study. These timelines are delicately interwoven on each other and cannot be seen as an obvious distinct time span. Real and imaginary are blended to portray the narrator's subconscious mind and mentality. The narrative skips a fixed period of time and travels over the unreliable planes of memory. He envisages half-remembered and imagined events that aid him to blend fact and fiction.

Having worked on multiple time scales, Ghosh succeeds to display temporal discontinuity in the individual and social domains and emphasizes the ambivalence regarding any relevant description of past and future, as they are fused together and are as vague as the smeared lines. He also blends history with fleeting memories, fact and fiction, reality and imagination, manipulating space-time, fracturing it, and disclosing general cultural interests.

\subsection{Independence}

The notion of travelling in mind, despite its seeming simplistic appearance, conveys a deep political message: independence. The fact that through visualizing places one can feel free from the invention of others, metaphorically implies that Indians can be disposed of modernism or so-called technology imposed on them by British colonizers. The only character opposing to such a viewpoint is lla who has travelled a lot but has seen a little. She is shown as a sample of dependent character that holds an opposite ideology. She gives full emphasis on the present and is physically and spiritually dependent on what is provided for her at the present time. She fails to traverse in past and future and prefers to enjoy using the already-prepared facilities that new modern world has bestowed to her.

The concept of separation and independence, both in private life and public affairs, is best exemplified in different parts of the story. The partition of the ancestral home is followed by brothers' insistence on dividing the doorways and 
even lavatory. The grandmother's expectation to see the borderlines between India and East Pakistan as vividly and clearly as they are seen on school atlases reinforces the idea that everything should stand on its own place. Her disapproval of Tridib and lla lies in the same point: Tridib has powerful influence on the narrator and Tha'mma does not allow him (narrator) to be separated from the family to which he belongs. The narrator has biological liaison to her grandmother (Tha'mma), so he should act and behave according to the moral principles of the family, and violation of such ethics may lead to anarchy. Likewise, she hates lla as she does not respect territorial and cultural issues.

\section{Conclusion}

The novel projects the consequences of colonization and the hardships and bewilderment it usually brings for those living in such environments, especially in the period of decolonization. This paper scrutinizes the overall content, message and structure of the narrative through postcolonial approach and attempts to substantiate that Ghosh has adroitly employed elements of postcolonialism to convey his theme. Throughout the novel the writer explicitly and implicitly emits sparks of postcolonial elements to show his interest in depicting the aftermath of colonization. The article, therefore, explores the overall structure of the novel through postcolonial approach and its main constituting elements such as obscurity, memory, imagination, identity, essentialism, otherness (alterity), ambivalence, nationalism, space/place, worlding, diaspora, hybridity, unbelonging, independence...etc.

The anonymity of the narrator, reference to alterity, otherness, and geographic dispersion (diaspora), as well as the application of hybridity in identity, characters, and even in the use of memory all allude to the fact that the whole narrative can best be comprehended within postcolonial framework. Certain concepts as alterity reinforce the idea that one can be independent from the others and their inventions; similarly, in concepts as essentialism the discussion of whatness in one's culture, race, ethnicity and nation is put forward. The application of ambivalence or coexistence of contradictory images, being similar and different at the same time, underlines the transformability of those entities, people, culture, and characters that are held identical and distinct simultaneously, and is best displayed in two neighboring towns of Dhaka and Calcutta. Moreover, numerous places and spaces are mentioned in this novel to highlight the significance of location, as they provide people with better understanding of self, their identities, environments and the world around. In this narrative, place finds an important role as it generates identity, gives prominence to language, culture and surroundings, and finally heightens one's nationalistic passion. Thus, displacement of characters, both practically or imaginatively, makes one being engaged in world and makes him or her being familiar with new findings. The outcome of such worlding process is that one gets released from the cocoon wrapped round him or her, and that it opens new horizons of the world in his or her outlook. It throws light on initial awareness of the social, psychological, and cultural inferiority of subaltern people who display their struggle for ethnic, cultural, and political autonomy. The writer's emphasis on memory and imagination is an implicit reference and encouragement to live independently. Furthermore, it helps the writer move freely in time to link past and present (hybridity). Through the element of hybridity the novel not only traverses beyond the boundaries of time, but also blends diverse characters, memories, nations, locations and history. It fuses fact and fiction, reality and unreality, to magnify the aftermath of colonization: unbelonging and the unpleasant experience of those who have witnessed various demarcations and felt delimitation with their own bones and flesh.

\section{Refrences}

Ashcroft, B. (2000). Post-Colonial Transformations. London: Routledge.

Augé, M. (1995). Non-places: Introduction to anthropology of super modernity. London, UK: S Verso.

Basu, R. (1994). Amitav Ghosh's Fiction - Turning the Full Circle. (N. Bharucha, \& V. Sarang, Eds.) Indian English Fiction 1980-90: An Assessment. , 151-160.

Boehmer, E. (1995). Colonial and Post-colonial Writing: Migrant Metaphors. Oxford: Oxford University Press.

Bose, B. (2002). Footnoting History: The Diasporic Imagination of Amitav Ghosh. In M. Paranjape (Ed.), Diaspora: Theories, Histories, Texts (pp. 235-45). New Delhi: Indialog.

Burgin, V. (1996). In/Different Spaces, Place and Memory in Visual Culture. Berkeley: California University Press.

Butt, N. (2008). Inventing or Recalling the Contact Zones? Transcultural Spaces in Amitav Ghosh's The Shadow Lines. Postcolonial Text , $4(3)$.

Gellner, E. (1994). Nationalism and High Cultures. In J. Hutchinson, \& A. D. Smith (Eds.), Nationalism (pp. 63-70). Oxford: Oxford University Press.

Ghosh, A. (2005). The Shadow Lines (11 ed.). New Delhi, India: Oxford University Press.

Hutchinson, J. (1987). The Dynamics of Cultural Nationalism. London: Harper/Collins.

James, L. (1999). Shadow Lines: Cross-Cultural Perspectives in the Fiction of Amitav Ghosh. In R. K. Dhawan (Ed.), The Novels of 
Amitav Ghosh (pp. 52-8). New Delhi, India: Sangam.

Kapadia, N. (1996). Imagination and Politics in Amitav Ghosh's The Shadow Lines. In V. Hirpal (Ed.), The New Indian Novel in English: A Study of the 1980s (pp. 201-10). New Delhi, India: Allied.

Kaul, A. N. (2003). A Reading of The Shadow Lines. In A. Ghosh, The Shadow Lines (11 ed., pp. 299-309). New Delhi, India: Oxford University Press.

Kaul, S. (2003). Separation Anxiety: Growing Up Inter/National in The Shadow Lines. In A. Ghosh, The Shadow Lines (11 ed., pp. 268286). New Delhi, India: Oxford University Press.

Kumar, P. (1999). Testimonies of Loss and Memory: Partition and the Haunting of a Nation. Interventions: International Journal of Postcolonial Studies 1, 2, 210-15.

Kumar, T. V. (2007). Postcolonial' Describes You as a Negative: An Interview with Amitav Ghosh. Interventions: International Journal of Postcolonial Studies 9, 1, 99-105.

Loomba, A. (2000). Colonialism/Postcolonialism. New York, USA: Routledge.

Mondal, A. A. (2003). Allegories of Identity: "Postmodern" Anxiety and "Postcolonial" Ambivalence in Amitav Ghosh's In an Antique Land and The Shadow Lines. The Journal of Commenwealth Literature , 38, 19-36.

Mukherjee, M. (2003). Maps and Mirrors: Co-ordinates of Meaning in The Shadow Lines. In A. Ghosh, The Shadow Lines (11 ed., pp. 255-267). New Delhi, India: Oxford University Press.

Prabhu, A. (2007). Hybridity, Limits, Transformations, Prospects. (E. C. Eze, \& A. Dirlik, Eds.) New York, USA: State University of New York Press.

Rajan, R. S. (2003). The Division of Experience in The Shadow Lines. In A. Ghosh, The Shadow Lines (11 ed., pp. 287-298). New Delhi, India: Oxford University Press.

Roy, A. G. (2012). Ordinary People on the Move: Subaltern Cosmopolitanisms in Amitav. Asiatic , 6 (1), 119.

Said, E. W. (1978). Orientalism: Western Conceptions of the Orient. New Delhi: Penguin Books.

Singh, S. (2005). The Routes of National Identity in Amitav Ghosh's The Shadow Lines. In P. Morey, \& A. Tickell (Eds.), Alternative Indias: Writing Nation and Communalism (pp. 161-80). Amsterdam, The Netherlands: Rodopi.

Vukanovic, M. B. (2009). Space and Time in Language and Literature. (L. G. Grumsa, Ed.) UK: Cambridge Scholers Publishing.

Warnes, C. (2009). Magical Realism and the Postcolonial Novel. London, UK: Palgrave Macmillan. 